\title{
13. (+)-Metathebainone, (+)-Morphothebaine, and Thebenine from Sinomenine ${ }^{1)}$
}

\author{
By Kakuji Goтo, м.J.A., and Izuru Yамамото \\ Department of Chemistry, Kitasato Institute, Tokyo, Japan
}

(Comm. Jan. 13, 1958)

The preparation of $(+)$-codeinone from sinomenine was greatly improved by hydrolysing codeinone dimethyl ketal, described by $\mathrm{H}$. Rapoport et al., in their short communication on its transformation into (-)-thebaine, although they did not give there a detailed condition of experiments. ${ }^{2}$

We started with the enol methyl ether of (+)-dihydrocodeinone (I), which was obtained easily after Homeyer's method. ${ }^{3)}$ The latter was converted into 7-bromodihydrocodeinone dimethyl ketal (II) either by treating it in methanol with $\mathrm{N}$-bromosuccinimide or by dissolving it in methyl hypobromite. The yield $(70 \%)$ seemed to be better in the former method. This dimethyl ketal was then heated with potassium ter.-amyl alcoholate $(0.5 \mathrm{~N})$ in a sealed tube at $130^{\circ}$ for five hours. The dimethyl ketal of (+)-codeinone was not isolated, but the content of the sealed tube was, after distilling off the ter.-amyl alcohol, directly hydrolysed with $2 \%$ hydrochloric acid at $75^{\circ}$ for thirty minutes. The yield of (+)-codeinone (III) was $c a .60 \%$, beside a small quantity of $(+)$-sinomeninone. The over-all yiled of $(+)$-codeinone from sinomenine was thus $12 \%$. As codeinone could be reduced by $\mathrm{NaBH}_{4}$ into codeine in $80 \%$ yield, ${ }^{4)}$ and morphine can be obtained from the latter in $35 \%$ yield, this method can be applied to the preparation of $(+)-$ morphine from sinomenine, without the use of 2,4-dinitrophenylhydrazine. The over-all yield of (t)-morphine is thus $c a .3 \%$, surpassing by $1 \%$ that of 1 -bromosinomeneine method..$^{5)}$

$(+)$-Codeinone was then transformed into (+)-metathebainone (IV), $(+)$-morphothebaine $(\mathrm{V})$, and thebenine (VI) by the well-known method of Knorr. ${ }^{6)}$ The physical properties of these three substances were compared with those of the respective optical antipode. They were naturally the same, except the direction of optical rotation in the former two. These were racemised with respective (-)-derivative.

It is noteworthy that through transformation of sinomenine into thebenine one and the same nitrogenous substance was obtained from sinomenine and morphine group, since all the other corresponding derivatives of sinomenine to those of morphine group had been the optical antipodes of the latter. 


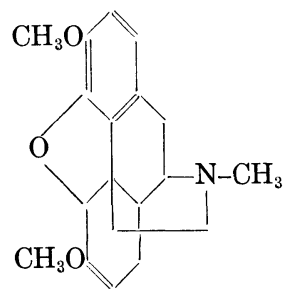

I

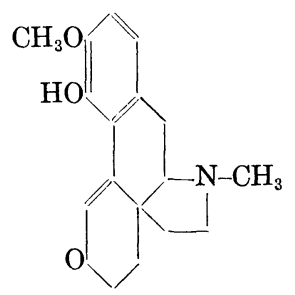

IV

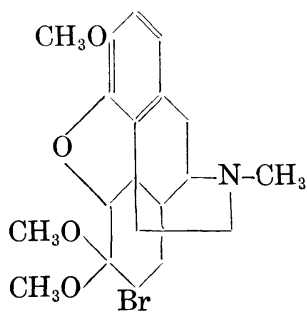

II<smiles>COc1ccc2c(O)c1Cc1cccc(c1O)C2N</smiles>

V

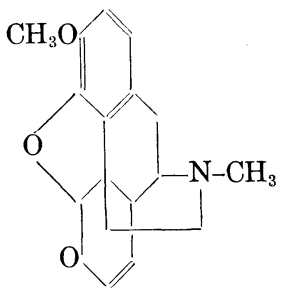

III

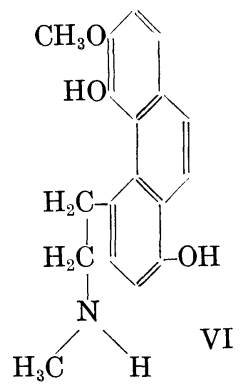

\section{Experimental}

(1) (+)-Dihydrocodeinone enol methyl ether (I). (+)-Dihydrocodeinone in this experiment was prepared either by boiling dihydrosinomenine with $50 \%$ sulphuric acid for one hour ${ }^{7)}$ or by heating sinomenine hydrochloride itself with stannous chloride and 50\% sulphuric acid first at $100^{\circ}$ for thirty minutes and then at $135^{\circ}$ for one hour. The heating at $100^{\circ}$ only gave $\beta$-dihydrosinomeninone alone $(50 \%)$. The yield of the both preparative ways is almost equal, namely $50-60 \%$. The former method requires the hydrogenation of sinomenine, but is fitted for the preparation of a large quantity.

The preparation of $(+)$-dihydrothebaine was carried out exactly after A. H. Homeyer. ${ }^{3}$ Only the commercial dimethyl sulphate was washed with dilute sodium bicarbonate solution before use. Yield 50\%. M.p. $162-163^{\circ}$. $[\alpha]_{\mathrm{D}}^{17}=+268.2^{\circ}$ (c 1.544, benzene). (Analysis. Calcd. for $\mathrm{C}_{19} \mathrm{H}_{23} \mathrm{O}_{3} \mathrm{~N}$ : C, 72.82; H, 7.40; N, 4.47; $\mathrm{CH}_{3} \mathrm{O}-$, 19.86. Found: C, 73.14; $\mathrm{H}, 7.51 ; \mathrm{N}, 4.48 ; \mathrm{CH}_{3} \mathrm{O}-$, 18.98).

(2) (+)-7-Bromodihydrocodeinone dimethyl ketal (II). A solution of (+)-dihydrothebaine (4 gr) in methanol $(60 \mathrm{cc})$ was added with $\mathrm{N}$ bromosuccinimide $(2.4 \mathrm{gr} ; 1 \mathrm{~mol})$ and left stand for 1.5 hours at room temperature. The addition product was extracted with chloroform from soda alkaline solution. The residue of the chloroform evaporation was recrystallised from methanol. Prisms. M.p. $117^{\circ}$. Yield $4 \mathrm{gr}(74 \%)$. $[\alpha]_{D}^{10}=+164.5^{\circ}$ (c 1.536, chlf.). (Analysis. Calcd. for $\mathrm{C}_{20} \mathrm{H}_{26} \mathrm{O}_{4} \mathrm{NBr}: \mathrm{C}$, 56.61; H, 6.17; N, 3.31; $\mathrm{Br}, 18.93 ; \mathrm{CH}_{3} \mathrm{O}-$, 21.94. Found: C, 56.67; H, $\left.6.20 ; \mathrm{N}, 3.18 ; \mathrm{Br}, 18.89 ; \mathrm{CH}_{3} \mathrm{O}-, 22.13\right)$. 
(3) (+)-Codeinone (III). A mixture of $0.54 \mathrm{gr}$ potassium in $28 \mathrm{cc}$ ter.-amyl alcohol and $2 \mathrm{gr}$ of ( + -)-7-bromodihydrocodeinone dimethyl ketal was heated in a sealed tube at $130^{\circ}$ (bath temp.) for five hours. The two lots were combined, diluted with water $(30 \mathrm{cc})$, added with $20 \%$ caustic soda solution $(20 \mathrm{cc})$, and extracted with chloroform. The chloroform layer, washed with water, gave $3.1 \mathrm{gr}$ of residue on vacuum evaporation. The isolation of $(+)$-codeinone dimethyl ketal was not however attempted. ${ }^{8)}$

The above residue was dissolved in $2 \%$ hydrochloric acid (70 cc) and warmed in a water bath at $75-80^{\circ}$ for half an hour. The acidic solution was then made alkaline with $20 \%$ caustic soda $(25 \mathrm{cc})$ and extracted with chloroform. The residue of the chloroform crystallised at once from ethyl acetate. M.p. $178^{\circ}$ (dec.), but one recrystallisation raised the m.p. to $186^{\circ}$. Yield $1.6 \mathrm{gr}$ (57\%).

Oxime, m.p. $212^{\circ}$; oxime-HCl, m.p. $259^{\circ}$ (dec.).

(4) (+)-Metathebainone (IV). (+)-Codeinone (400 mg), conc. hydrochloric acid $(7 \mathrm{cc})$, and stannous chloride $(1.2 \mathrm{gr})$ were put together in a pressure bottle, and heated in a boiling water bath for twenty minutes. The reaction mixture was made alkaline with $\mathrm{NaHCO}_{3}$, and the whole base was extracted with chloroform. From this chloroform layer, the phenolic base was reextracted with $10 \%$ caustic soda solution. The $(+)$-metathebainone, isolated from this aqueous layer crystallised in long prisms from methanol. M.p. $115-118^{\circ}$ (foaming). Yield $80 \mathrm{mg}$. $\quad[\alpha]_{\mathrm{D}}^{18}=+416.3^{\circ}$ (c 0.92 , benzene). (Analysis. Calcd. for $\mathrm{C}_{18} \mathrm{H}_{21} \mathrm{O}_{3} \mathrm{~N} \cdot \mathrm{CH}_{3} \mathrm{OH} ; \mathrm{C}, 68.88 ; \mathrm{H}, 7.55 ; \mathrm{N}, 4.23$. Found: C, 68.80; H, 7.67; N, 4.50).

It gives a green ferric chloride reaction, a red halochromy with conc. sulphuric acid and forms yellowish red sodium salt with $5 \%$ caustic soda.

Oxime. Needles from methanol. M.p. $198^{\circ}$ (uncor., foamed at 130 $-140^{\circ}$ and again solidified).

$d, l$-Metathebainone. $21 \mathrm{mg}$ each of $(+)$ - and (-)-metathebainone were dissolved in methanol and the combined solution was concentrated, when $d, l$-metathebainone crystallised out in stout prisms. M.p. $230^{\circ}$ (dec.). $\alpha= \pm 0^{\circ}$ (c 0.3 , methanol).

(5) (+)-Morphothebaine (V). A mixture of (+)-codeinone (0.4 gr) and conc. hydrochloric acid (2 cc) was heated in a sealed tube in a boiling water bath for two hours. From the gray clump of the acid hydrochloride, $170 \mathrm{mg}$ of normal hydrochloride was obtained after recrystallisation from water. M.p. $259^{\circ}$ (dec.). The free base was obtained by usual way. M.p. $197^{\circ}$ (dec.). $[\alpha]_{\mathrm{D}}^{6}=+130.0^{\circ}$ (c 0.774 , alc.). (Analysis. Calcd. for $\mathrm{C}_{18} \mathrm{H}_{19} \mathrm{O}_{3} \mathrm{~N}: \mathrm{C}, 72.70 ; \mathrm{H}, 6.44 ; \mathrm{N}, 4.71$. Found: C, $72.50 ; \mathrm{H}, 6.24 ; \mathrm{N}, 4.75)$. The ferric chloride reaction is green. 
$d, l$-Morphothebaine. $19 \mathrm{mg}$ each of $(+)$ - and (-)-morphothebaine were dissolved in methanol and the combined solution was evaporated. The racemic body crystallised out while hot. M.p. $187^{\circ}$ after one recrystallisation from methanol. $\alpha= \pm 0^{\circ}$ (c 0.2 , methanol).

(6) Thebenine hydrochloride (VI) from (+)-codeinone. $0.2 \mathrm{gr}$ of $(+)$-codeinone was treated with hot dil. hydrochloric acid $(14 \%)$ in the same way just as Knorr described. A clear yellow solution was resulted, from which thebenine hydrochloride crystallised out on seeding with that obtained from thebaine. Yield $30 \mathrm{mg}$. M.p. 231-234 ${ }^{\circ}$ (dec.), also the mixed m.p. with that obtained from thebaine. (Analysis. Calcd. for $\mathrm{C}_{18} \mathrm{H}_{19} \mathrm{O}_{3} \mathrm{~N} \cdot \mathrm{HCl}$ : C, 64.76; H, 6.04; N, 4.20; Cl, 10.62. Found: C, 64.63; H, 6.10; N, 4.22; Cl, 10.77). The hydrochloride gives a green colour with ferric chloride and a reddish violet halochromy with conc. sulphuric acid.

The above analyses were carried out in the Chemical Laboratory of the Sankyo Pharmaceutical Co., for which we thank heartily.

\section{References}

1) The 71st Comm. on Sinomenine.

2) H. Rapoport, H. N. Reist, and C. H. Lovell: J. A. C. S., 78, 5128 (1956).

3) A. H. Homeyer: J. Org. Chem., 21, 370 (1956).

4) M. Gates: J. A. C. S., 75, 4340 (1953). Repeated also by the authors with the same result.

5) Proc. Japan Acad., 33, 477 (1957).

6) L. Knorr: B., 37, 3171 (1904); ibid., 36, 3074 (1903).

7) Acta Phytochimica, 15, 187 (1949).

8) (+)-Codeinone dimethyl ketal crystallises well in large prisms. M.p. $138^{\circ}$. $[\alpha]_{\mathrm{D}}^{11}=$ $+236.0^{\circ}$ (c 1.016, EtOH) (Methoxyl. Calcd. for $\mathrm{C}_{20} \mathrm{H}_{25} \mathrm{O}_{4} \mathrm{~N}: 27.11$. Found: 26.89). 